\title{
Organic Phosphate Binding Inhibits High pH t-Isomerization of the $\beta$-Chain in Straw-coloured Fruit Bat (Eidolon helvum) Haemoglobin
}

\author{
Adedayo A. Fodeke* \\ Department of Chemistry, Obafemi Awolowo University, Ile-Ife, 200055, Nigeria. \\ Received 21 July 2017, revised 16 November 2017, accepted 20 November 2017.
}

\begin{abstract}
Understanding the systematic structural changes accompanying allosteric effector binding to haemoglobin should provide some clues to the understanding of structure-function relationship in other multimeric enzymes. The affinities of the CysF9[93] $\beta$ sulfhydryl group of oxy-, carbomonoxy- and aquomet-derivatives of straw-coloured fruit bat (Eidolon helvum) haemoglobin (SCFB-Hb) for 5,5'-dithiobis(2-nitrobenzoate) (DTNB) were measured in the range $5.6 \leq \mathrm{pH} \leq 9.0$ using stripped and inositol hexakisphosphate (inosito- $\mathrm{P}_{6}$ ) bound haemoglobin. The data were analyzed on the basis of findings that the tertiary structure of the product of the reaction of DTNB with haemoglobin CysF9[93] $\beta$ sulfhydryl group exists in two conformations; $r$ and $t$. The result shows that the affinity of DTNB for SCFB-Hb in both $\mathrm{r}$ and $\mathrm{t}$ conformations are coupled to the ionizations of two ionizable

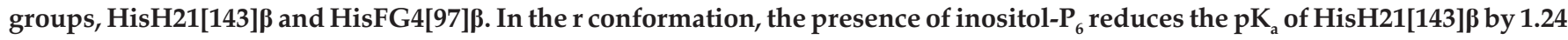
units and that of HisFG4[97] $\beta$ by 2.74. In the $t$ conformation, inositol- ${ }_{6}$ raises the $\mathrm{pK}_{\mathrm{a}}$ of HisH21[143] $\beta$ by $1.10 \mathrm{pK}_{\mathrm{a}}$ units whereas that of HisFG4[97] $\beta$ was increased by $0.78 \mathrm{pK}_{\mathrm{a}}$ units. Change in $\mathrm{pK}_{\mathrm{a}}$ of ionization of the ionizable groups and isomerization of the tertiary conformations are important modulators of organic phosphate binding.
\end{abstract}

KEYWORDS

Sulfhydryl group, inositol hexakisphosphate, ionizable group, stripped haemoglobin, $\mathbf{r} \leftrightarrow \mathrm{t}$ isomerization, 5,5'-dithiobis(2nitrobenzoate).

\section{Introduction}

In mammalian haemoglobins, the reaction of 5,5'-dithiobis(2nitrobenzoate) (DTNB) with CysF9[93] $\beta$ sulfhydryl group has been used as indicator of tertiary and the quaternary structure. ${ }^{1-3}$ This reaction occurs reversibly. Therefore, the $\mathrm{r} \leftrightarrow \mathrm{t}$ transition which occurs at the tertiary level is also in dynamic equilibrium when DTNB is bound to the CysF9[93] $\beta$ sulfhydryl group. It must be stated that this is different from $\mathrm{R}$ (relaxed) and $\mathrm{T}$ (tensed) quaternary conformations, formed, respectively, in the absence and presence of salt bridges. In the $r$ state, the sulfhydryl group is cis to the terminal amino group, but cis to the carbonyl end in the $t$ state. Transitions between $r$ and $t$ tertiary conformations are accompanied by change in the $\mathrm{pK}_{\mathrm{a}} \mathrm{s}$ of ionization of the ionizable groups that are linked to the reaction of DTNB with the CysF9[93] $\beta$ haemoglobin sulfhydryl group. ${ }^{4}$

The affinity of human haemoglobin for oxygen has been shown to be regulated by the organic phosphate, 2,3-bisphosphoglycerate (2,3-BPG). ${ }^{5-8} 2,3-\mathrm{BPG}$ is a small molecule with a high density of negative charge. It is an allosteric effector which can bind to ligated and unligated haemoglobin in a process that is believed to be proton driven and involves oxygen uptake. ${ }^{7}$ Previous work has demonstrated that the most striking functional changes in haemoglobin occur when allosteric effectors get fully bound to oxy-haemoglobin, the consequences of which include a dramatic decrease in the oxygen affinity, an enhanced Bohr effect, and almost disappearance of oxygen cooperativity, emulating a Root effect-like behaviour. ${ }^{9-10}$ ValNA1[1] $\beta$, HisNA2[2] $\beta$, LysEF6[82] $\beta$ and HisH21[143] $\beta$ have been implicated in the binding of 2,3-BPG to haemoglobin. ${ }^{9}$ The same

* To whom correspondence should be addressed. E-mail: afodeke@ yahoo.co.uk residues have been reported to bind inositol- $\mathrm{P}_{6}$, an organic phosphate, which like 2,3-BPG, has a high density of negative charge. ${ }^{6,11}$ Increase in $\mathrm{pH}$ has been reported to reduce the binding affinity of 2,3-BPG. This finding has been attributed to ionization of the cationic groups that become neutral side chains.

Bats are the only known flying mammals. Though the primary structure of the haemoglobin of a number of bat species has been determined, the primary structure of SCFB- $\mathrm{Hb}$ has not been characterized. It is expected that like human haemoglobin, inositol- $\mathrm{P}_{6}$ should also alter the tertiary structure of SCFB-Hb. However, no experimental data have been reported on the magnitude and nature of change in tertiary or quaternary structure of any species of bat haemoglobin due to organic phosphate binding.

While organic phosphate binding is known to alter the $\mathrm{pK}_{\mathrm{a}}$ of the ionizable groups of a specific tertiary structure ( $\mathrm{r}$ or $\mathrm{t}$ ) due to quaternary structure changes, the $\mathrm{pK}_{\mathrm{a}}$ changes of either stripped or organic phosphate bound haemoglobin should arise from $\mathrm{r} \leftrightarrow \mathrm{t}$ transition (tertiary level changes) only. If however, binding of organic phosphate results in significant tertiary conformation changes in the haemoglobin structure, the change in $\mathrm{pK}_{\mathrm{a}}$ resulting from the $\mathrm{r} \leftrightarrow \mathrm{t}$ transition in stripped haemoglobin should be significantly different from that in inositol- $\mathrm{P}_{6}$ bound haemoglobin. Value of $\mathrm{K}_{\mathrm{rt}}$, the equilibrium constant of isomerization given by $\mathrm{K}_{\mathrm{rt}}=\left(\mathrm{Hb}_{4}\right)_{\mathrm{t}} /\left(\mathrm{Hb}_{4}\right)_{\mathrm{r}}$ in organic phosphate bound haemoglobin should also be significantly different from its value in the stripped haemoglobin.

Hitherto, the way by which organic phosphates perform the function of regulating oxygen binding has not been fully understood. It is with the aim to quantifying the magnitude of tertiary 
level conformation changes and understanding the sequence of processes culminating in the binding to, and dissociation of organic phosphate from haemoglobin that we embarked on the study reported herein.

\section{Materials and Methods}

\subsection{Materials}

All reagents and chemicals are similar to those previously reported..$^{1-3}$

\subsection{Preparation of Haemoglobin}

SCFB oxyhaemoglobin was prepared as described previously. ${ }^{1-3}$ The major difference here is in the use of $11.5 \mathrm{~g} \mathrm{dm}^{-3}$ saline solution rather than $9.5 \mathrm{~g} \mathrm{dm}^{-3}$ at $5{ }^{\circ} \mathrm{C}$ for washing the red blood cells. Carbonmonoxyhaemoglobin was obtained as described earlier. ${ }^{1-3}$ Full conversion to the carbonmonoxy derivative was confirmed with previously obtained spectrum of carbonmonoxyhaemoglobin. ${ }^{4}$ Conversion to aquomethaemoglobin was carried out by oxidation of oxyhaemoglobin with two-fold molar excess $\mathrm{K}_{3} \mathrm{Fe}(\mathrm{CN})_{6}$. Each derivative was passed through a Dintzis ion exchange column to remove the endogenous ions. ${ }^{3,12}$ The concentration of the haemoglobin derivatives were determined as described earlier. ${ }^{3}$

\subsection{Determination of p-(Hydroxymercuri)benzoic Acid (p-MB) Reactive Sulfhydryl Group}

The number of p-MB reactive sulfhydryl groups was determined four times by titration of $5 \mu \mathrm{mol} \mathrm{dm}{ }^{-3}$ carbonmonoxyhaemoglobin tetramer in phosphate buffer $\mathrm{pH} 7.6$, ionic strength $50 \mathrm{mmol} \mathrm{dm}^{-3}(\mathrm{NaCl})$ with $420 \mu \mathrm{mol} \mathrm{dm}{ }^{-3} \mathrm{p}-\mathrm{MB}$ as described by Boyer, et. al. ${ }^{13}$

\subsection{Determination of DTNB Reactive Sulfhydryl Group}

The number of sulfhydryl groups reacting with DTNB was determined by titration of the $2.5 \mu \mathrm{mol} \mathrm{dm}{ }^{-3}$ (tetramer) carbonmonoxyhaemoglobin, four times in phosphate buffer $\mathrm{pH}$ 7.6, ionic strength $50 \mathrm{mmol} \mathrm{dm}^{-3}(\mathrm{NaCl})$ with $0.5 \mathrm{mmol} \mathrm{dm}^{-3}$ DTNB stock solution as described elsewhere. ${ }^{1,14}$

\subsection{Determination of Equilibrium Constant of Reaction of Stripped Haemoglobin with DTNB}

Stock DTNB used for equilibrium studies was prepared as described earlier. ${ }^{2}$ Method used for the determination of equilibrium constant had been previously described. ${ }^{2}$ The mean of at least six replicate equilibrium constant determinations at each $\mathrm{pH}$ of the experiments was calculated. The $\mathrm{pH}$ of the reaction solutions was determined at the end of each experiment.

\subsection{Determination of the Equilibrium Constant in the Presence of Inositol- $P_{6}$}

$2.5 \times 10^{-6} \mathrm{dm}^{3}$ of $50 \mathrm{mmol} \mathrm{dm}{ }^{-3}$ stock inositol- $\mathrm{P}_{6}$ which had been titrated to $\mathrm{pH} 6.7$ with $1.0 \mathrm{~mol} \mathrm{dm}^{-3} \mathrm{HCl}$ was added to haemoglobin to make inositol- $\mathrm{P}_{6}$ final concentration $50 \times 10^{-6}$ mol dm${ }^{-3}$ in a $25 \mathrm{~cm}^{3}$ volumetric flask. The equilibrium reaction with DTNB were carried out as described earlier. ${ }^{2}$ The mean equilibrium constant values of at least six replicate experiments at each $\mathrm{pH}$ of reaction was determined.

\section{Data Analysis}

\subsection{Calculation of Equilibrium Constant from Experimental Data}

Various equilibria accompanying the reaction between haemo- globin sulfhydryl group and DTNB are described by Equation 1 below:

$\mathrm{PSH}+\mathrm{DTNB} \stackrel{Q_{S H}}{\rightleftharpoons} \mathrm{H}^{+}+\mathrm{PS}^{-}+\mathrm{DTNB} \stackrel{K_{E Q}}{\stackrel{\mathrm{H}^{+}}{\mathrm{PST}} \cdot \mathrm{TNB}+\mathrm{TNB} \stackrel{\mathrm{Q}_{T N B}}{\rightleftharpoons}}$

$\mathrm{K}_{\mathrm{EQ}}$ is related to the other quantities in Equation 1 by:

$$
\mathrm{K}_{\mathrm{EQ}}=\frac{\left[\mathrm{TNB}^{-}\right]^{2}\left\{1+\frac{\left[\mathrm{H}^{+}\right]}{\mathrm{Q}_{\mathrm{TNB}}}\right\}\left\{1+\frac{\left[\mathrm{H}^{+}\right]}{\mathrm{Q}_{\mathrm{SH}}}\right\}}{[\mathrm{PSH}]_{\mathrm{TOT}}-\left[\mathrm{TNB}^{-}\right]\left\{1+\frac{\left[\mathrm{H}^{+}\right]}{\mathrm{Q}_{\mathrm{TNB}}}\right\}\left\{[\mathrm{DTNB}]_{\mathrm{TOT}}-\left[\mathrm{TNB}^{-}\right]\left\{1+\frac{\left[\mathrm{H}^{+}\right]}{\mathrm{Q}_{\mathrm{TNB}}}\right\}\right\}}
$$

A detailed derivation of Equation 2 has been described before. ${ }^{2}$ In Equations 1 and $2 \mathrm{PSH}$ is the haemoglobin with CysF9[93] $\beta$ in its protonated form which does not react with non-mercurial sulfhydryl reagents; ${ }^{14-16}$ PS $^{-}$is the corresponding thiol anion form which reacts with DTNB; PS.TNB is the mixed disulfide, the product of reaction of $\mathrm{PS}^{-}$with $\mathrm{DTNB}$; $\mathrm{TNB}^{-}$is the chromophoric product of DTNB reaction with haemoglobin, whose concentration is determined spectrophotometrically at $412 \mathrm{~nm}$. The protonated form of $\mathrm{TNB}^{-}$is $\mathrm{TNBH} ; \mathrm{Q}_{\mathrm{SH}}$ and $\mathrm{Q}_{\mathrm{TNB}}$ are the ionization constants of CysF9[93] $\beta$ and $\mathrm{TNBH}$, respectively; $\mathrm{K}_{\mathrm{EO}}$ is the equilibrium constant for the formation of the mixed disulfide (PS.TNB) from the reaction of DTNB with haemoglobin sulfhydryl group.

In calculating $\mathrm{K}_{\mathrm{EQ}}$ with Equation 2, $\mathrm{pQ}_{\mathrm{TNB}}$ value of 5.27 was used. ${ }^{2}$ The $\mathrm{pQ}_{\mathrm{SH}}$ of $\mathrm{Cys}[\mathrm{F} 9] 93 \beta$ lies between 8.0 and 8.6. ${ }^{16-18}$ We therefore, assumed a $p Q_{\mathrm{SH}}$ value of 8.3. These $\mathrm{Q}_{\mathrm{SH}}$ and $\mathrm{Q}_{\mathrm{TNB}}$ values together with the $\mathrm{TNB}^{-}$concentration measured at $412 \mathrm{~nm}$ from the absorbance of $\mathrm{TNB}^{-}$at specific $\mathrm{pH}$ values were substituted into Equation 2 to obtain $\mathrm{K}_{\mathrm{EQ}}$. It is assumed that the absorbance of TNBH at $412 \mathrm{~nm}$ is insignificant. ${ }^{2}$ The standard error in the determination of $\mathrm{K}_{\mathrm{EQ}}$ is about $10 \%$.

\subsection{Fitting of Experimental Data to Various Equilibria Steps in the Theoretical Model}

The number and $\mathrm{pK}_{\mathrm{a}}$ of the ionizable groups linked to the $\mathrm{pH}$ dependence of the $\mathrm{K}_{\mathrm{EQ}}$ of the reaction of DTNB with the haemoglobin were analyzed based on previous findings that: (i) CysF9[93] $\beta$ sulfhydryl group of liganded haemoglobin exist in two tertiary conformations; cis to the terminal amino group (r-conformation) and cis to the carbonyl group (t-conformation) ${ }^{20-21}$ and (ii) that these two sulfhydryl conformations are coupled to transitions between the two tertiary structures in dynamic equilibrium. ${ }^{4,22}$ In the experiment reported here, the reaction of DTNB with three derivatives of liganded stripped haemoglobin (haemoglobin that is free of organic phosphate) and three derivatives of inositol- $\mathrm{P}_{6}$ bound haemoglobin were studied. Inositol- $\mathrm{P}_{6}$ is known to favour T conformation. ${ }^{23-25}$

In determining the number and the nature of the DTNBlinked ionizable groups, we employed Scheme 1.,25-28

Scheme 1 is more detailed form of Equation 1 in which the ionization of groups on the haemoglobin species are shown. In Scheme $1, n$ is the total number of ionizable groups linked to the equilibrium reaction of DTNB with the haemoglobin sulfhydryl group. $\mathrm{H}_{\mathrm{n}-\mathrm{i}+1} \mathrm{PSH}(\mathrm{i}=1,2 \ldots, \mathrm{n}+1)$ denotes the various protonated forms of the haemoglobin which do not react with DTNB and are therefore omitted from Scheme 1. The protons arising from the ionization of the ionizable groups linked to the reaction of DTNB with the haemoglobin sulfhydryl group are also omitted for clarity. $\mathrm{H}_{\mathrm{n}-\mathrm{i}+1} \mathrm{PS}^{-}(\mathrm{i}=1,2 \ldots, \mathrm{n}+1)$ are species in which the sulfhydryl group is in its thiolate anion form, the form that reacts with DTNB; Species marked with subscripts ' $r$ ' and ' $t$ ' are those in which the haemoglobin sulfhydryl is in the $\mathbf{r}$ - and t tertiary 


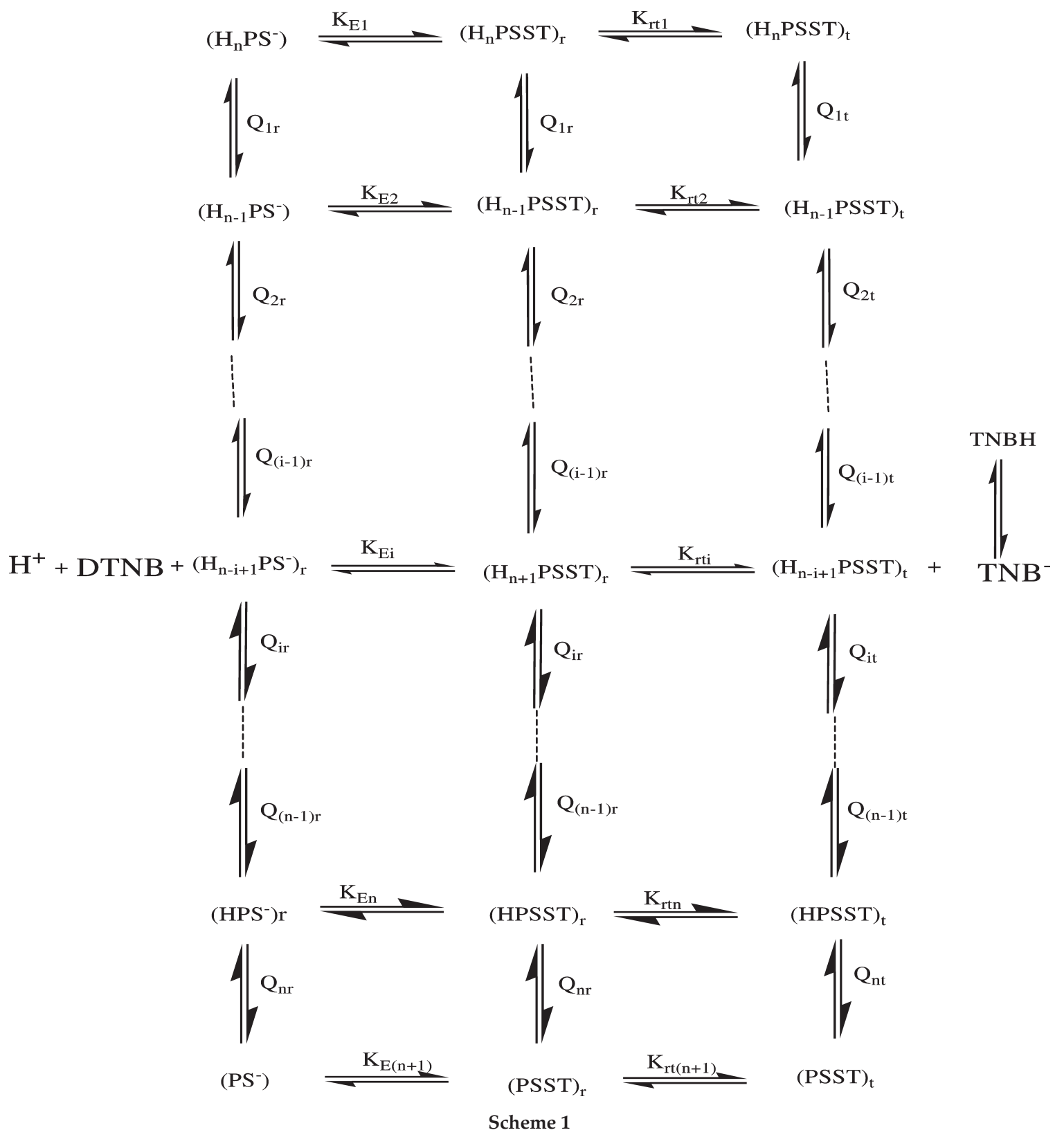

isomeric forms, respectively. The various proton ionization constants are presented as $Q_{\text {ir }}$ (for the r-isomer) or $Q_{i t}$ (for the $\mathrm{t}$-isomer) $(\mathrm{i}=1,2, \ldots, \mathrm{n})$ to distinguish them from $\mathrm{K}_{\mathrm{Ei}}(\mathrm{i}=1,2, \ldots$ $\mathrm{n}+1$ ), the equilibrium constants for the reaction of the $\mathrm{H}_{\mathrm{n}-\mathrm{i}+1} \mathrm{PS}^{-}$ species with DTNB. The equilibrium constant of transition at high $\mathrm{pH}$ for the $\mathrm{r} \leftrightarrow \mathrm{t}$ tertiary conformational transition is given by $\mathrm{K}_{\mathrm{rt}(\mathrm{n}+1)}$.

The relationship between $\mathrm{K}_{\mathrm{EQ}}$ and the parameters in Scheme 1 is given by: ${ }^{4}$

$K_{E Q}=\frac{K_{E(n+1)}\left\{1+\sum_{i=1}^{n}\left(H^{+}\right)^{n-i+1}\left(\prod_{j=i}^{n} Q_{j r}\right)^{-1}+K_{r(n+1)}\left\{1+\sum_{i=1}^{n}\left(H^{+}\right)^{n-i+1}\left(\prod_{j=i}^{n} Q_{j t}\right)^{-1}\right\}\right\}}{\left\{1+K_{E(n+1)}\left\{\sum_{i=1}^{n}\left(H^{+}\right)^{n-i+1}\left(\prod_{j=i}^{n} Q_{j r}\right)^{-1} K_{E i}{ }^{-1}\right\}\right\}}$

Equation 3 was used to fit the dependence of $-\log \mathrm{K}_{\mathrm{EQ}}$ on $\mathrm{pH}$. The value of $\mathrm{n}$ (in Equation 3) that gives the best fit of the calculated curve through the experimental data points is the number of the ionizable groups linked to the equilibrium reaction of haemoglobin sulfhydryl group with DTNB. The best fit values of $p Q_{i r}$ and $p Q_{i t}$ give the ionization constants of the ionizable groups in the ' $r$ ' and ' $\mathrm{t}$ ' tertiary conformations, respectively. $\mathrm{K}_{\mathrm{Ei}}\{\mathrm{i}=1,2 \ldots(\mathrm{n}+1)\}$ are the equilibrium constants of each reacting species. Fitting of the experimental data to Equation 3 were performed using Micromath Scientist software (Salt Lake City, Utah) with a script of the relationship between $\mathrm{K}_{\mathrm{EQ}}$ and $\mathrm{pH}$ according to Equation 3.

\section{Results}

\subsection{Number of Reactive Sulfhydryl Groups}

The amino acid sequence of SCFB-Hb has not been previously reported. However, the haemoglobin amino acid sequences of the bat species which had been previously characterized showed that: Egyptian fruit bat (Rousettus aegyptiacus) haemoglobin has sulfhydryl groups at positions G11[104] $\alpha, \mathrm{F} 9[93] \beta$ and G14[112] $\beta_{; 9}$ mouse-eared bat (Myotis velifer) haemoglobin has sulfhydryl groups at positions G11[104] $\alpha, \mathrm{G} 18[111] \alpha$ and F9[93] $\beta_{;}^{30}$ pallid bat (Antozous pallidus) haemoglobin has sufhydryl groups at positions G11[104] $\alpha, \mathrm{H} 1[123] \beta, \mathrm{G} 18[111] \alpha$ and F9[93] $\beta .^{31}$ In tomb bat (Taphozous georgianus) haemoglobin, the sulfhydryl groups are located at positions G11[104] $\alpha$, 
G14[112] $\beta$, and F9[93] ${ }^{32}$ Of these sulfhydryl groups, only CysG11[104] $\alpha$ and CysG14[112] $\beta$ are known to be masked to both DTNB, and p-MB. We therefore expect SCFB-Hb, being a member of the same family, to have reactive sulfhydryl group at position $\mathrm{F} 9[93] \beta$, in addition to one or two other positions. Surprisingly, Boyer titration of the haemoglobin with $\mathrm{p}-\mathrm{MB}$ repeated three times gave a mean value of $2.05 \pm 0.12$ sulfhydryl group per tetramer (figure not shown).

Also, DTNB titrations of SCFB-Hb repeated three times (figure not shown) gave a mean value of $2.02 \pm 0.06$ titratable sulfhydryl groups. This shows that bat haemoglobin has only two reactive sulfhydryl groups per tetramer. Sulfhydryl groups at position F9[93] is known to be reactive with both Boyer's and Ellman's reagent in all mammalian and avian haemoglobins. ${ }^{2-4,11,12,17,23,26,27}$ We therefore assigned the only pair of $\mathrm{p}-\mathrm{MB}$ and DTNB reactive sulfhydryl group in the bat haemoglobin to position F9[93]ß.

\subsection{Reaction of DTNB with SCFB CysF9[93]ß of Oxyhaemoglobin}

The strong $\mathrm{pH}$ dependences of the negative logarithm to base 10 of the equilibrium constant $\left(-\log _{10} \mathrm{~K}_{\mathrm{EQ}}\right)$ of the reaction of the stripped oxyhaemoglobin and the inositol- $\mathrm{P}_{6}$ bound SCFB oxyhaemoglobin with DTNB are presented in Fig. 1. Each data point is obtained from the mean value of at least six replicate experiments. The curves through the experimental data points were best fit curves using Equation 3 (cf. Scheme 1) with $n=2$, together with the fitting parameters reported in Table 1 column 2. The fitting parameters of Table 2 column 2 using Equation 3 (cf. Scheme 1) with $n=2$ report the data of inositol- $\mathrm{P}_{6}$ bound oxyhaemoglobin. The equilibrium constant values of both the stripped and the inositol- $\mathrm{P}_{6}$ bound haemoglobin are quite similar in the range $5.6 \leq \mathrm{pH} \leq 7.0$. Above $\mathrm{pH} 7.0$, however, the

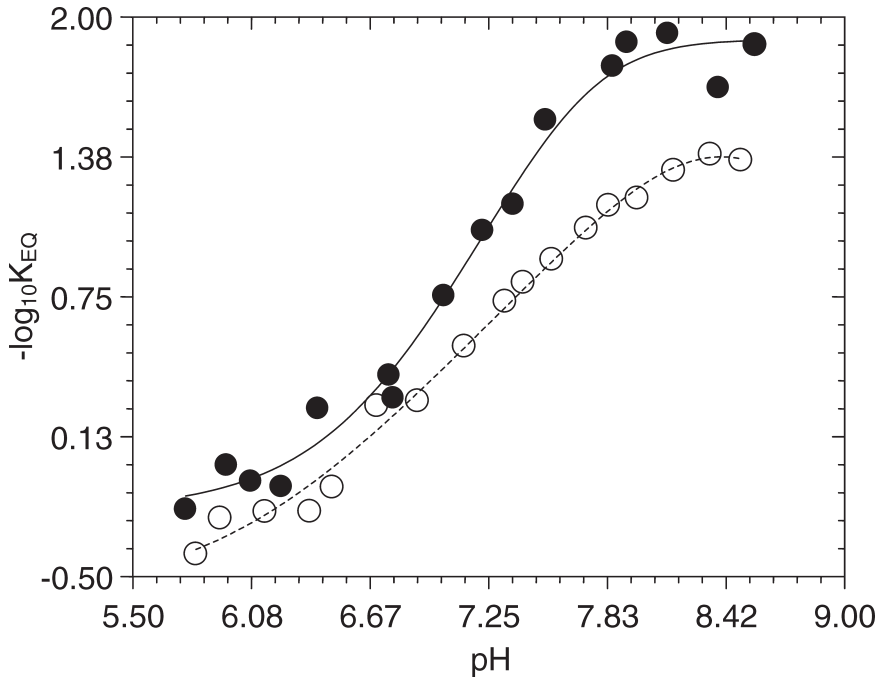

Figure 1 Reaction of 5,5'-dithiobis(2-nitrobenzoate), DTNB, with the CysF9[93] $\beta$ sulfhydryl group of SCFB oxyhaemoglobin. Dependence of the equilibrium constant on $\mathrm{pH}$ : stripped oxyhaemoglobin, open circle and broken curve; inositol- $\mathrm{P}_{6}$ bound oxyhaemoglobin, filled circle and full curve. Conditions: $30^{\circ} \mathrm{C}$; phosphate buffers, $\mathrm{pH}$ 5.6-7.8; borate buffers, $\mathrm{pH}$ 8.0-9.0; ionic strength, $50 \mathrm{mmol} \mathrm{dm}^{-3}$; haemoglobin concentration, $25 \mu \mathrm{mol} \mathrm{dm}{ }^{-3}$ in reacting sulfhydryl groups, that is $50 \mu \mathrm{mol}$ (heme) $\mathrm{dm}^{-3}$. Each data point is the mean of at least six replicate experiments and is subject to a standard error of about \pm 0.1 in the logarithm unit. The curves through the data points are the best-fit theoretical lines calculated with Equation 3 in the text with $n=2(c f$. Scheme 1$)$

equilibrium constant of the reaction of stripped haemoglobin gets increasingly greater than that of the inositol- $\mathrm{P}_{6}$ bound haemoglobin with increasing $\mathrm{pH}$.

Table 1 Reaction of DTNB with stripped haemoglobin: parameters of the best-fit curves through the open circles in Figs. 1-3 using Scheme 1 and Equation 3 in the text with $n=2$.

\begin{tabular}{lrcrc}
\hline Parameter & Oxy & Carbonmonoxy & Aquomet & Mean \pm S.D. \\
\hline $\mathrm{pQ}_{1 \mathrm{r}}$ & 5.69 & 7.24 & 6.74 & $6.56 \pm 0.58$ \\
$\mathrm{pQ}_{1 \mathrm{t}}$ & 9.13 & 9.58 & 9.37 & $9.36 \pm 0.15$ \\
$\mathrm{pQ}_{2 \mathrm{r}}$ & 8.39 & 7.95 & 8.93 & $8.42 \pm 0.34$ \\
$\mathrm{pQ}_{2 \mathrm{t}}$ & 7.78 & 7.81 & 7.25 & $7.61 \pm 0.24$ \\
$\mathrm{~K}_{\mathrm{E} 3} / \mathrm{K}_{\mathrm{E} 2}$ & 69.52 & 760.76 & 15.93 & $282.07 \pm 319.13$ \\
$\mathrm{~K}_{\mathrm{E} 3} / \mathrm{K}_{\mathrm{E} 1}$ & 162.37 & 174.17 & 6.77 & $114.44 \pm 71.78$ \\
$\mathrm{pK}_{\mathrm{E} 3}$ & 0.49 & 0.37 & 1.05 & $0.64 \pm 0.27$ \\
$\mathrm{~K}_{\mathrm{r} 3}$ & 2.75 & 5.26 & 4.37 & $4.13 \pm 0.92$ \\
\hline
\end{tabular}

The last column gives the values of the parameter \pm standard deviation (S.D.).

Table 2 Reaction of DTNB with haemoglobin in the presence of inositol- $\mathrm{P}_{6}$ : parameters of the best-fit curves through the filled circles in Figs. 1-3 using Scheme 1 and Equation 3 in the text with $n=2$.

\begin{tabular}{lrcrc}
\hline Parameter & Oxy & Carbonmonoxy & Aquomet & Mean \pm S.D. \\
\hline $\mathrm{pQ}_{1 \mathrm{r}}$ & 5.06 & 5.35 & 5.55 & $5.32 \pm 0.17$ \\
$\mathrm{pQ}_{1 \mathrm{t}}$ & 10.80 & 10.20 & 10.37 & $10.46 \pm 0.23$ \\
$\mathrm{pQ}_{2 \mathrm{r}}$ & 5.45 & 5.70 & 5.88 & $5.68 \pm 0.15$ \\
$\mathrm{pQ}_{2 \mathrm{t}}$ & 8.32 & 8.82 & 8.03 & $8.39 \pm 0.29$ \\
$\mathrm{~K}_{\mathrm{E} 3} \mathrm{~K}_{\mathrm{E} 2}$ & 20.96 & 53.19 & 8.15 & $27.43 \pm 17.17$ \\
$\mathrm{~K}_{\mathrm{E} 3} \mathrm{~K}_{\mathrm{E} 1}$ & 649.82 & 677.11 & 984.33 & $770.42 \pm 142.61$ \\
$\mathrm{pK}_{\mathrm{E} 3}$ & 1.90 & 1.56 & 1.92 & $1.79 \pm 0.15$ \\
$\mathrm{~K}_{\mathrm{rt} 3}$ & 0.0002 & 0.0012 & 0.0011 & $0.00084 \pm 0.00042$ \\
\hline
\end{tabular}

The last column gives the values of the parameter \pm standard deviation (S.D.). 


\subsection{Reaction of DTNB with SCFB CysF9[93]ß of Carbonmonoxyhaemoglobin}

The experimental data points in Fig. 2 were fitted as described in section 4.2 above, using the fitting parameters reported in Table 1 column 3 for the stripped carbonmonoxyhaemoglobin and that reported in Table 2 column 3 for the inositol- $\mathrm{P}_{6}$ bound carbonmonoxyhaemoglobin. The curve of the $\mathrm{pH}$ dependences of the $-\log _{10} \mathrm{~K}_{\mathrm{EQ}}$ of the reaction of DTNB with stripped and inositol- $\mathrm{P}_{6}$ bound SCFB carbonmonoxyhaemoglobin are both sigmoidal (Fig. 2). Below $\mathrm{pH} 7.3$, the $\mathrm{K}_{\mathrm{EQ}}$ values of the stripped haemoglobin were lower than that of the inositol- $\mathrm{P}_{6}$ bound carbonmonoxyhaemoglobin at equivalent $\mathrm{pHs}$. In the range $7.3 \leq \mathrm{pH} \leq 7.7$, the values of the $\mathrm{K}_{\mathrm{EQ}}$ of both stripped and inositol- $\mathrm{P}_{6}$ bound haemoglobin were quite comparable at identical pHs. Above $\mathrm{pH}$ 8.0, the $\mathrm{K}_{\mathrm{EQ}}$ values of the stripped haemoglobin are somewhat higher than that of the organic phosphate bound haemoglobin at the corresponding $\mathrm{pHs}$.

\subsection{Reaction of DTNB with SCFB CysF9[93]ß Aquomethaemoglobin}

The experimental data of the $\mathrm{pH}$ dependences of $-\log _{10} \mathrm{~K}_{\mathrm{EQ}}$ for the reaction of DTNB with stripped aquomethaemoglobin are plotted along with that of reaction of DTNB with inositol- $\mathrm{P}_{6}$ bound haemoglobin for comparison (Fig. 3). The $\mathrm{K}_{\mathrm{EQ}}$ value is strongly dependent on $\mathrm{pH}$. The data were well fitted with $\mathrm{n}=2$ as described in sections 4.2 and 4.3. The curve through the experimental data points of stripped haemoglobin reaction with DTNB was fitted with parameters reported in Table 1 column 4. That of inositol- $\mathrm{P}_{6}$ bound aquomethaemoglobin reaction was fitted with the parameters reported in Table 2 column 4 . It is evident that the $\mathrm{K}_{\mathrm{EQ}}$ values for the reaction of the stripped aquomethaemoglobin with DTNB are greater than that of the reaction of inositol- $\mathrm{P}_{6}$ bound haemoglobin with DTNB at equivalent $\mathrm{pH}$, over the entire $\mathrm{pH}$ range of the experiment. However, the differences in equilibrium constant of the reaction were minimized in the range $7.3 \leq \mathrm{pH} \leq 7.5$.

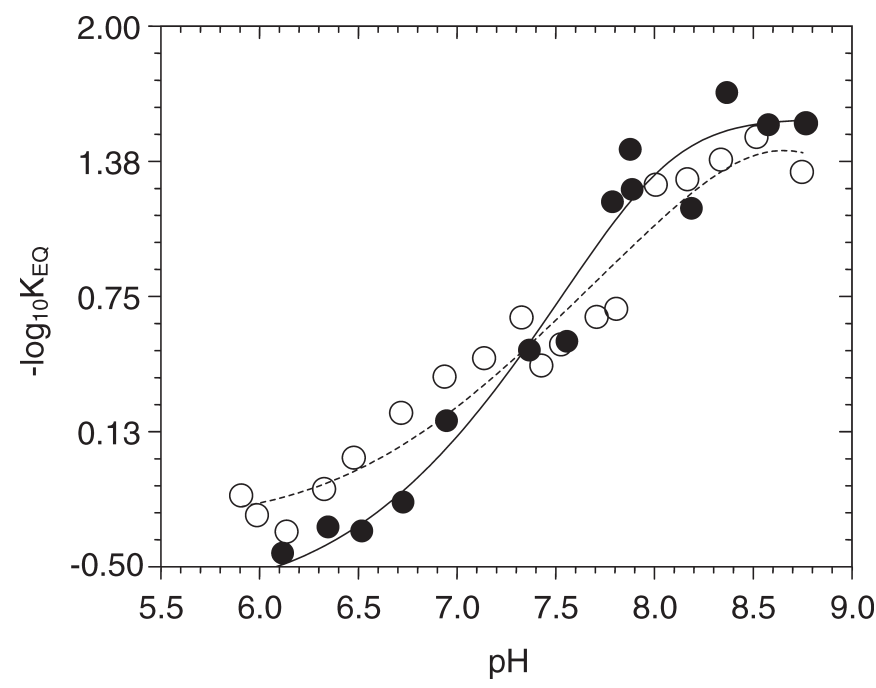

Figure 2 Reaction of 5,5'-dithiobis(2-nitrobenzoate), DTNB, with the CysF9[93] $\beta$ sulfhydryl group of SCFB carbonmonoxyhaemoglobin. Dependence of the equilibrium constant on $\mathrm{pH}$ : stripped carbonmooxyhaemoglobin, open circle and broken curve; inositol- $\mathrm{P}_{6}$ bound carbonmonoxyhaemoglobin, filled circle and full curve. Conditions were as described for Fig. 1. Each data point is the mean of at least six replicate experiments and is subject to a standard error of about \pm 0.1 in the logarithm unit. The curves through the data points are the best-fit theoretical lines calculated with Equation 3 in the text with $n=2$ (cf. Scheme 1).

\section{5. $\mathrm{pK}_{\mathrm{a}}$ Values and $\mathrm{K}_{\mathrm{rt}}$ the Equilibrium Constant of $\mathbf{r} \leftrightarrow \mathbf{t}$ Transition}

In order to calculate the equilibrium constant for $\mathrm{r} \leftrightarrow \mathrm{t}$ transition, $\mathrm{K}_{\mathrm{rt}}$, we made use of Scheme 1 . According to which at equilibrium:

$$
\begin{aligned}
& -\log _{10} \mathrm{~K}_{\mathrm{r} 22}=p Q_{2 \mathrm{r}}+\left(-\log _{10} \mathrm{~K}_{\mathrm{rt} 3}\right)-\mathrm{pQ}_{2 \mathrm{t}} \\
& \text { and } \\
& -\log _{10} \mathrm{~K}_{\mathrm{rt} 1}=p Q_{1 \mathrm{r}}+\left(-\log _{10} \mathrm{~K}_{\mathrm{rt} 2}\right)-\mathrm{pQ}_{1 \mathrm{t}}
\end{aligned}
$$

For the stripped haemoglobin, all the parameters on the right side of Equation 5 were obtained from the mean value of the fitting parameters of the experimental data in Table 1. For inositol- $\mathrm{P}_{6}$ bound haemoglobin, the value of the parameters on the right side of Equation 5 were obtained from the mean values of the fitting parameters in Table 2. Once $\mathrm{K}_{\mathrm{rt2}}$ was determined using Equation 5, its value and Equation 6 with appropriate parameter from the mean values reported in Tables 1 or 2 (as applicable) was used to calculate $K_{r t 1}$. The values of $K_{r t i}(i=1,2$ and 3) so calculated for stripped haemoglobin were presented in Table 3. Similar data for inositol- $\mathrm{P}_{6}$ bound haemoglobin are summarized in Table 4.

\section{Discussion}

\subsection{How does Inositol- $P_{6}$ affect the Equilibrium Constant of Isomerization, $\mathrm{K}_{\mathrm{rt}}$ ?}

The reaction of all the three SCFB haemoglobin derivatives were carried out under identical $\mathrm{pH}$ conditions and were analyzed based on previous finding by Shaanan, ${ }^{21}$ that human oxyhaemoglobin exists as a mixture of two tertiary conformations ( $\mathrm{r}-$ and $\mathrm{t}-$ ) which are in dynamic equilibrium in solution. ${ }^{21}$ We suggest that under a given condition, the $\mathrm{pK}_{\mathrm{a}}$ of the ionizable groups linked to these two haemoglobin conformations will be different if the isomerization process results in change in the environment of the ionizable groups. By similar hypothesis, the $\mathrm{pK}_{\mathrm{a}}$ of ionizable groups linked to the equilibrium reaction of

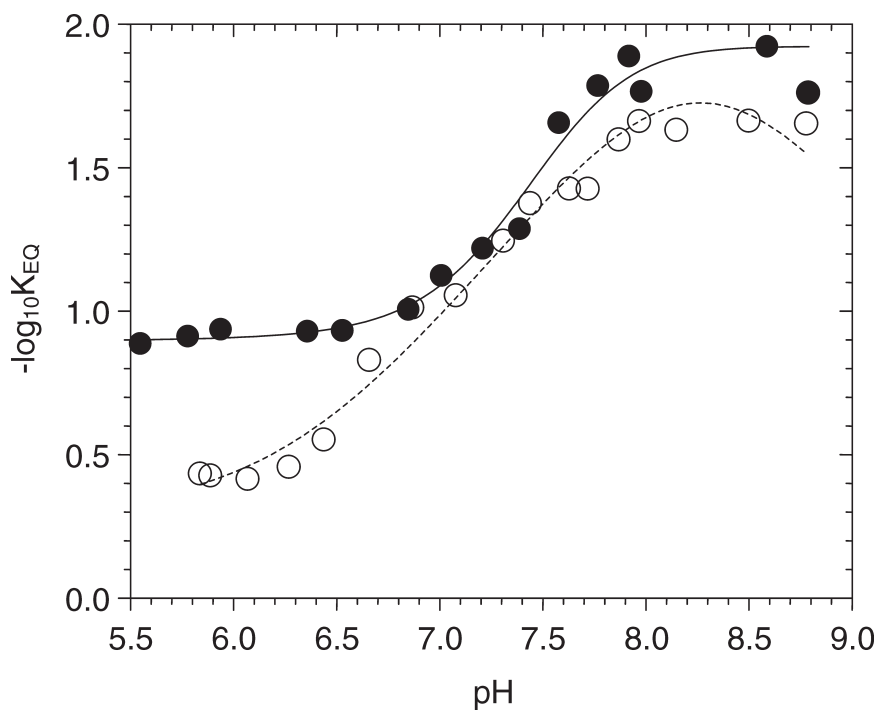

Figure 3 Reaction of 5,5'-dithiobis(2-nitrobenzoate), DTNB, with the CysF9[93] $\beta$ sulfhydryl group of SCFB aquomethaemoglobin. Dependence of the equilibrium constant on $\mathrm{pH}$ : stripped aquomethaemoglobin, open circle and broken curve; inositol- $\mathrm{P}_{6}$ bound aquomethaemoglobin, filled circle and full curve. Conditions were as described for Fig. 1. Each data point is the mean of at least six replicate experiments and is subject to a standard error of about \pm 0.1 in the logarithm unit. The curves through the data points are the best-fit theoretical lines calculated with Equation 3 in the text for $\mathrm{n}=2$ (cf. Scheme 1). 
Table 3 Mean isomerization data of the different ionization species of stripped SCFB haemoglobin. Proportion of t-isomer in the various ionization states are shown in brackets.

\begin{tabular}{cccc}
\hline \multicolumn{1}{c}{$\mathrm{i}$} & 1 & 2 & 3 \\
\hline $\mathrm{H}_{\mathrm{n}-\mathrm{i}+1} \mathrm{PS}^{-}(\mathrm{i}=1,2 \ldots, \mathrm{n}+1)$ & $\mathrm{H}_{2} \mathrm{PS}^{-}$ & $\mathrm{HPS}^{-}$ & $\mathrm{PS}^{-}$ \\
$\mathrm{K}_{\mathrm{rti}}$ & $403.5(99.75 \%)$ & $0.64(39.01 \%)$ & $4.13(80.51 \%)$ \\
$\Delta \mathrm{G}_{\mathrm{r} \leftrightarrow \mathrm{t}} / \mathrm{kJ} \mathrm{mol}^{-1}$ & -15.115 & 1.124 & -3.572 \\
\hline
\end{tabular}

Table 4 Mean isomerization data of the different ionization species of SCFB haemoglobin in the presence of inositol- $\mathrm{P}_{6}$. Proportion of t-isomer in the various ionization states are shown in brackets.

\begin{tabular}{cccc}
\hline \multicolumn{1}{c}{$\mathrm{i}$} & 1 & 2 & 3 \\
\hline $\mathrm{H}_{\mathrm{n}-\mathrm{i}+1} \mathrm{PS}^{-}(\mathrm{i}=1,2 \ldots, \mathrm{n}+1)$ & $\mathrm{H}_{2} \mathrm{PS}^{-}$ & $\mathrm{HPS}^{-}$ & $\mathrm{PS}^{-}$ \\
$\mathrm{K}_{\mathrm{rti}}$ & $59466.95(99.998 \%)$ & $0.4308(30.11 \%)$ & $0.00084(0.08 \%)$ \\
$\Delta \mathrm{G}_{\mathrm{r} \leftrightarrow \mathrm{t}} / \mathrm{kJ} \mathrm{mol}^{-1}$ & -27.693 & 2.121 & 17.84 \\
\hline
\end{tabular}

DTNB with CysF9[93]ß sulfhydryl group in stripped haemoglobin should be significantly different from that of inositol- $\mathrm{P}_{6}$ bound haemoglobin. Inositol- $\mathrm{P}_{6}$, a molecule with high density of negative charge should create an environment which is different from that in the stripped haemoglobin around the ionizable groups.

It must be noted that whereas, the $\mathrm{pK}_{\mathrm{a}}$ values obtained for the two ionizable groups of the stripped haemoglobin were raised as a result of $\mathrm{r} \rightarrow \mathrm{t}$ isomerization in the kinetic experiment carried out earlier with SCFB haemoglobin, ${ }^{33}$ only the first ionizable group has its $\mathrm{pK}_{\mathrm{a}}$ raised in the equilibrium constant experiment. In addition, the $\mathrm{K}_{\mathrm{rt} 3}$ value obtained in the equilibrium experiment at high $\mathrm{pH}$ is about 40 times greater than that determined using kinetic data. ${ }^{33}$ This latter discrepancy can be the consequence of incomplete binding of DTNB to haemoglobin in kinetic reaction compared to equilibrium experiment where DTNB binding to haemoglobin is maximum. We therefore, submit that at high $\mathrm{pH}$, DTNB binding favours conversion of stripped haemoglobin from r-isomer to t-isomer. The result also suggests that as the DTNB gets bound to the haemoglobin, the $\beta$-chains might get progressively converted from $r$ conformation to the $t$ conformation. This discovery is consistent with the observation that the mean $\mathrm{K}_{\mathrm{rt} 3}$ (the $\mathrm{K}_{\mathrm{rt}}$ at high $\mathrm{pH}$ ) of inositol- $\mathrm{P}_{6}$ bound haemoglobin is $c a$. three orders of magnitude lower than the $\mathrm{K}_{\mathrm{rt} 3}$ of stripped haemoglobin (compare the mean $\mathrm{K}_{\mathrm{rt} 3}$ in Tables 3 \& 4). This suggests that organic phosphate binding might be acting by strongly favouring r-isomer formation as opposed to t-isomer at high $\mathrm{pH}$. The following observations from the comparison of Tables 3 and 4 are also noteworthy: (i) low $\mathrm{pH}$ had a drastic effect of converting the haemoglobin almost entirely to the t-isomer in both stripped and inositol- $\mathrm{P}_{6}$ bound haemoglobin; (ii) at intermediate $\mathrm{pH}$, in the stripped haemoglobin, the t-isomer is about $39 \%$ which is reduced to about $30 \%$ t-isomer in organic phosphate bound haemoglobin; (iii) at high $\mathrm{pH}$, whereas, the population of t-isomer in stripped haemoglobin is as high as $c a .80 \%$, in organic phosphate bound haemoglobin, the population of t-isomer is less than $0.1 \%$. This suggests that inositol- $\mathrm{P}_{6}$ acts by strongly favouring the t-isomer at low $\mathrm{pH}$, and progressively favouring $\mathrm{r}$-isomer with increasing $\mathrm{pH}$. This is indicative of $\mathrm{pH}$ dependent organic phosphate binding for physiological function. It also shows that the organic phosphate acts by altering the equilibrium between $r$ and $t$ tertiary conformation of the haemoglobin chains.

\subsection{Assignment of the First Ionizable Group}

The values of the mean $\mathrm{pQ}_{1 \mathrm{r}}$ (in the $\mathrm{r}$-isomer) and $\mathrm{pQ}_{1 \mathrm{t}}$ (in the t-isomer) are 6.56 and 9.36, respectively, for the first ionizable group of the stripped haemoglobin. The corresponding values of $\mathrm{pQ}_{1 \mathrm{r}}$ and $\mathrm{pQ}_{1 \mathrm{t}}$ for the inositol- $\mathrm{P}_{6}$ bound haemoglobin are 5.32 and 10.46, respectively. Based on previous assignment in human carbonmonoxyhaemoglobin, ${ }^{34}$ the ionizable group was assigned to HisH21[143] $\beta$. The assignment made in this report was based on the presumption that the bat haemoglobin also possess Histidine at $\mathrm{H} 21[143] \beta$ position. The mean $\mathrm{pK}_{\mathrm{a}}$ of this ionizable group in human carbonmonoxyhaemoglobin as determined using ${ }^{1} \mathrm{H}$ NMR technique was 5.65. ${ }^{34}$

In the bat stripped haemoglobin, the implication of these results is that isomerization from $\mathrm{r}$ - to $\mathrm{t}$ - conformation raises the $\mathrm{pK}_{\mathrm{a}}$ of the first ionizable group by about $2.80 \mathrm{pK}_{\mathrm{a}}$ units. Similar isomerization of the inositol- $\mathrm{P}_{6}$ bound haemoglobin leads to 5.14 $\mathrm{pK}_{\mathrm{a}}$ unit increase in the same ionizable group. This is almost double the change in $\mathrm{pK}_{a}$ of the ionizable group resulting from isomerization from $\mathrm{r}$ - to $\mathrm{t}$ - tertiary conformation observed in the stripped haemoglobin. This suggests that organic phosphate binding increase the change in $\mathrm{pK}_{\mathrm{a}}$ of isomerization. This may not be unconnected with the strong binding of organic phosphate to HisH21[143] $\beta$ site. The increased change in $\mathrm{pK}_{a}$ in presence of organic phosphate was achieved by lowering the $\mathrm{pK}_{\mathrm{a}}$ of ionization of HisH21[143] $\beta$ in the r-isomer and raising it (making it more difficult for it to ionize) in the t-isomer, compared to the stripped haemoglobin. The values of the $\mathrm{pK}_{\mathrm{a}} \mathrm{s}$ of this ionizable group in the two isomeric forms of both stripped and inositol- $\mathrm{P}_{6}$ bound haemoglobin, suggest that in t-isomer, the ionizable group might be brought nearer to an anionic side chain which stabilizes the protonated form of the histidine as opposed to the deprotonated form. On the other hand, in the r-isomer conformation, HisH21[143] $\beta$ might be brought nearer a cationic side chain or a neutral residue. This can at least semi quantitatively account for the higher value of the $\mathrm{pK}_{\mathrm{a}}$ of this ionizable group in t-isomer of the organic phoshphate bound haemoglobin compared the stripped haemoglobin. Judging from close examination of the $\beta$-chain three-dimensional structure of haemoglobin, the HisH21[143[ $\beta$ ] of SCFB haemoglobin, should be located near AspG1[99] $\beta$ and Glu3[101] $\beta$. HisH21[143[ $\beta]$ should be brought closer to these negatively charged groups when salt bridge is formed between HisHC3[146] $\beta$ and AspFG1[94] $\beta$ in the presence of inositol- $\mathrm{P}_{6}$. This is supposed to significantly raise the $\mathrm{pK}_{\mathrm{a}}$ of the HisH21[143[ $\beta$ in the presence of organic phosphate in agreement with our findings. We therefore suggest that in the presence of inositol- $\mathrm{P}_{6}$, increase in $\mathrm{pK}_{\mathrm{a}}$ change on isomerization from $\mathrm{r}$ - to $\mathrm{t}$-isomer compared to stripped haemoglobin arises from HisH21[143[ $\beta$ being brought nearer to 
AspG1[99] $\beta$ and Glu3[101] $\beta$ in the t-isomer in the inositol- $\mathrm{P}_{6}$ bound haemoglobin.

\subsection{Assignment of the Second Ionizable Group}

The mean $\mathrm{pK}_{\mathrm{a}} \mathrm{s}$ of the second ionizable group in the stripped haemoglobin described by $\mathrm{pQ}_{2 \mathrm{r}}$ and $\mathrm{pQ}_{2 \mathrm{t}}$ are 8.42 and 7.61, respectively. This suggests that $\mathrm{r}$ - to t-isomerization results in 0.81 $\mathrm{pK}_{\mathrm{a}}$ unit reduction. In the presence of saturating amount of inositol- $\mathrm{P}_{6}$ on the other hand, isomerization from $\mathrm{r}$ - to $\mathrm{t}$ - conformation results in change in $\mathrm{pK}_{\mathrm{a}}$ of the second ionizable from 5.68 to 8.39. This translates to $2.71 \mathrm{pK}_{\mathrm{a}}$ unit increase. These values show that $\mathrm{pK}_{\mathrm{a}}$ change in the second ionizable group arising from $\mathrm{r} \leftrightarrow \mathrm{t}$ isomerization in inositol- $\mathrm{P}_{6}$ bound haemoglobin is about 3.3 times greater than that of stripped haemoglobin. Again, we see here that inositol- $\mathrm{P}_{6}$ significantly increases the change in $\mathrm{pK}_{\mathrm{a}}$ of $\mathrm{r} \rightarrow \mathrm{t}$ isomerization compared to stripped haemoglobin.

Based on previous assignment, ${ }^{36}$ we apportioned the ionizable group characterized by $\mathrm{pQ}_{2 \mathrm{r}}$ and $\mathrm{pQ}_{2 \mathrm{t}}$ to the Histidine group at position FG4[97] $\beta$. Close examination of the amino acid sequences of human haemoglobin and bat species whose amino acid sequences have been previously characterized show that FG4[97] $\beta$ is surrounded by negatively charged amino acid residues GluF6[90] $\beta$, AspFG1[94] $\beta$, AspG1[99] $\beta$ and GluG3[101] $\beta .^{29-32}$ These residues should raise the $\mathrm{pK}_{\mathrm{a}}$ of histidine above the typical value of 6.0 for an isolate histidine residue. This is consistent with the $\mathrm{pK}_{\mathrm{a}}$ values assigned to FG4[97] $\beta$ in the stripped haemoglobin. Also, the mean $\mathrm{pK}_{\mathrm{a}}$ value of $5.68 \mathrm{ob}$ tained in the presence of organic phosphate can be rationalized based on salt bridge formation between HisHC3[146] $\beta$ and AspFG1[94] $\beta$. Organic phosphate favour r-isomer at high $\mathrm{pH}$ and is expected to bring HisFG4[97] $\beta$, a group that must have been completely ionized at high $\mathrm{pH}$, nearer to LysFG2[95] $\beta$, a positively charged amino residue with $\mathrm{pK}_{\mathrm{a}}$ value of 10.53 for the isolated group. This should lower the $\mathrm{pK}_{\mathrm{a}}$ of HisFG4[97] $\beta$ and stabilize the r-isomer as observed in this experiment. The three-dimensional structure of haemoglobin reveals that FG4[97] $\beta$ position is within ionic atmosphere of $\mathrm{F} 9[93] \beta$ position. Its reaction should therefore be linked to FG4[97] $\beta$ position. The $\mathrm{pK}_{\mathrm{a}}$ of HisFG4[97] $\beta$ previously reported for liganded mammalian haemoglobin is $c a .7 .75 .^{36}$ This value is in good agreement with $p Q_{2 t}$ value of 7.61 obtained in our experiment.

\subsection{Effect of Equilibrium Constant of Isomerization, $K_{\mathrm{rt}}$ values on Organic Phosphate Binding}

The results reported in this paper shows that greater increase in the $\mathrm{pK}_{\mathrm{a}}$ of the fist ionizable group occurred when the $\beta$-chains changes from $\mathrm{r}$ - to $\mathrm{t}$ - conformation in the presence of inositol- $\mathrm{P}_{6}$, than in the stripped haemoglobin. This suggests that the isomerization process is important in regulating the binding affinity of organic phosphate. In stripped haemoglobin, at low $\mathrm{pH}$, the proportion of t-isomer is $c a .99 .75 \%$. At high $\mathrm{pH}$, it is barely reduced to about $80.5 \%$ (see Table 3 ). Since the proportion of $\mathrm{t}$-isomer in the haemoglobin $\beta$-chain of stripped haemoglobin at both low and high $\mathrm{pH}$ is high, and the $\mathrm{pK}_{\mathrm{a}}$ of HisH21[143] $\beta$ in the t-isomer is high (ca. 9.36) and HisH21[143] $\beta$ remains essentially protonated over the entire $\mathrm{pH}$ of the experiment. The consequence of this is that the affinity of the stripped haemoglobin for organic phosphate remains essentially high at both low and high $\mathrm{pH}$.

In the presence of organic phosphate however, at low $\mathrm{pH}$, the proportion of t-isomer was $c a$. $100 \%$. This proportion reduces drastically with increasing $\mathrm{pH}$, with the r-isomer rising to ca. 99.92\% at high $\mathrm{pH}$. This ensures that HisH21[143] $\beta$ is almost entirely protonated (positively charged) at low $\mathrm{pH}$, but mostly deprotonated (neutral) at high $\mathrm{pH}$. The consequence of which is high affinity of the haemoglobin for organic phosphate (reduced affinity for oxygen) at low $\mathrm{pH}$. Protonation of histidine residue of the haemoglobin at low $\mathrm{pH}$, increased affinity of haemoglobin for organic phosphate and the attendant reduction in the affinity of haemoglobin for oxygen leads to increased physiological $\mathrm{pH}$. Increase in the proportion of $\mathrm{r}$-isomer (the low $\mathrm{pK}_{\mathrm{a}}$ form of HisH21[143] $\beta$ ) accompanying increase in $\mathrm{pH}$ in the presence of organic phosphate, ensures that increase in $\mathrm{pH}$ results in the ionization of HisH21[143]ß. The consequence of this is lowering of the affinity of HisH21[143] for the organic phosphate with increasing $\mathrm{pH}$. This may be used to account for the reported cooperativity of oxygen binding to haemoglobin. Previous findings have shown that HisH21[143] makes the most contribution (ca. $71 \%$ ) to the acid Bohr effect at pH 5.1. ${ }^{34}$

\subsection{Equilibrium Constant of Isomerization, $\mathrm{K}_{\mathrm{rt}}$ Values and HisFG4[97] $\beta$}

As noted in the previous section for the stripped haemoglobin, the t-isomer dominates at both low and high $\mathrm{pH}$. The $\mathrm{pK}_{\mathrm{a}}$ of HisFG4[97] $\beta$ in the t-isomer of the stripped haemoglobin is ca. 7.61. This value is barely lower than the $\mathrm{pK}_{\mathrm{a}}$ value of 8.42 for the same ionizable group in the r-isomer. Therefore, HisFG4[97] $\beta$ remains essentially protonated in the physiological $\mathrm{pH}$ range ( $\mathrm{pH}$ 6.9-7.2). Based on our data, it can only be deprotonated (converted to the neutral form) above $\mathrm{pH} 7.62$. The implication of this is higher affinity of the ionizable group for organic phosphate at acidic $\mathrm{pH}$ and over the entire physiological pH range. Again, this shows that in the absence of organic phosphate, HisFG4[97] $\beta$ contribute to higher affinity of the haemoglobin for organic phosphate at physiological $\mathrm{pH}$.

However, in the presence of inositol- $\mathrm{P}_{6}$, as observed earlier, the t-isomer population of $c a .100 \%$ at low $\mathrm{pH}$ reduces sharply to a population of less than $0.1 \%$ at high $\mathrm{pH}$ (the proportion of $\mathrm{r}$ isomer rises to about $99.9 \%$ ). It should again be noted that while $\mathrm{r}$-isomer of this ionizable group is characterized by low $\mathrm{pK}_{\mathrm{a}}$ value of 5.68 in the inositol- $\mathrm{P}_{6}$ bound haemoglobin, the t-isomer has a $\mathrm{pK}_{\mathrm{a}}$ value of 8.39. This shows that at low $\mathrm{pH}$ (below $\mathrm{pH}$ 5.68), the protonated form of the residue with high affinity for organic phosphate dominate. Whereas, at high $\mathrm{pH}$, the deprotonated form of the ionizable group which has low affinity for organic phosphate dominates, if the dominating conformation is the r-isomer. It should be emphasized from this findings that the stripped haemoglobin possesses high affinity for organic phosphate at low and high $\mathrm{pH}$. Lowering of the affinity of HisFG4[97] $\beta$ at high $\mathrm{pH}$, in the presence of organic phosphate is achieved because $\mathrm{r}$ - conformation with low $\mathrm{pK}_{\mathrm{a}}$ is favoured. This is a further indication that isomerization is critical for the regulation of organic phosphate binding to haemoglobin.

\section{Conclusion}

This study has shown quantitatively that isomerization process is important in regulating organic phosphate binding, and by extension oxygen binding to haemoglobin under different $\mathrm{pH}$ conditions. We demonstrated that the $\mathrm{pK}_{\mathrm{a}}$ change on isomerization from $r$ - to $t$ - conformation for the first ionizable group is 1.84 times greater in the presence of organic phosphate bound haemoglobin than the stripped haemoglobin. In the second ionizable group, the $\mathrm{pK}_{\mathrm{a}}$ change is 3.34 times greater in organic phosphate bound haemoglobin than in stripped haemoglobin. This is a strong indication that organic phosphate regulates the function of haemoglobin by altering both the $\mathrm{pK}_{\mathrm{a}}$ of the ionizable groups and altering the equilibrium constant of isomerization. 
The good quality of the theoretical fit to the experimental data with only two ionizable groups; (HisH21[143] $\beta$ and HisFG6[97] $\beta$ ) in isomerizing $\beta$-chain tertiary conformations suggests that HisEF1[77] $\beta$ the third ionizable group which was present in human haemoglobin might be either absent or unable to ionize in SCFB-Hb. Egyptian Fruit bat haemoglobin has histidine at position EF1[77] $\beta,^{29}$ but in tomb bat, mouse-eared bat, and pallid bat haemoglobins, position EF1[77] $\beta$ is occupied by asparagine, a neural but uncharged side chain. ${ }^{30-32}$ At present, amino acid sequences of SCFB haemoglobin has yet to be characterized for any categorical statement about this to be made. It would therefore be necessary to carryout similar experiment using other mammalian haemoglobin that are known to possess histidine at position EF1[77] $\beta$ for a more definite conclusion to be made.

\section{Acknowledgement}

The author is grateful to the Department of Chemistry, Obafemi Awolowo University, for the material support for this work.

\section{References}

1 K.O. Okonjo and A.A. Fodeke, Reversible reaction of 5,5'-dithiobis(2nitrobenzoate) with the hemoglobins of the domestic cat: acetylation of terminal group of the $\beta$ chain transforms the complex $\mathrm{pH}$ dependence of the apparent second order rate constant to a simple form. Biophys Chem., 2005, 119, 196-204.

2 K.O. Okonjo, A.A. Fodeke and T.A. Kehinde, Reversible reaction of 5,5'-dithiobis(2-nitrobenzoate) with the hemoglobins of the domestic cat: variation of the equilibrium and reverse rate constants with $\mathrm{pH}$ Biophys. Chem., 2006,121, 65-73.

3 K.O. Okonjo, T.A. Adediji, A.A. Fodeke, O. Adeboye and C.V. Ezeh, Transition of hemoglobin between two tertiary conformations: determination of equilibrium and thermodynamic parameters from the reaction of 5,5'-dithiobis(2-nitrobenzoate) with the CysF9[93]ß sulfhydryl group. Biophys. Chem., 2007, 128, 56-62.

4 K.O. Okonjo, M.O. Olatunde, A.A. Fodeke and J.O. Babalola, Bohr effect of human hemoglobin A: magnitude of negative contributions determined by the equilibrium between two tertiary structures. Biophys. Chem., 2014, 190-191, 41-49.

5 A. Arnone, X-ray diffraction study of binding of 2,3-diphosphoglycerate to human deoxyhaemoglobin, Nature, 1972, 237, 146-149.

6 A. Arnone and M.F. Perutz, Structure of inositol hexaphosphatehuman deoxyhaemoglobin complex, Nature, 1974, 249, 34-36.

7 J. Brygier, S.H. de Bruine, P.M.D. Van Hoof and H.S. Rollema, The interaction of organic phosphate with human and chicken haemoglobin, Eur. J. Biochem., 1975, 60, 379-383

8 K.O. Okonjo, C.O. Aboluwoye, J.O. Babalola and I.A. Usanga, Organic phosphate-binding groups electrostatically linked to the reactivity of the CysF9[93] $\beta$ sulfhydryl group of haemoglobin. J. Chem. Soc. (Far.Trans.) 1995, 91, 2095-2100.

9 R.E. Benesch, R.Benesch and C.I. Yu, The oxygenation of haemoglobin in the presence of 2,3-Diphosphoglycerate. Effect of temperature $\mathrm{pH}$, ionic strength and haemoglobin concentration, Biochemistry, 1969, 8, 2567-2571.

10 A. Tsuneshige, R. Park and T. Yonetani, Heterotrophic effectors control the haemoglobin function by interacting with its $\mathrm{T}$ and $\mathrm{R}$ states a new view on the principle of allostery. Biophys. Chem., 2002, 98, 49-63.

11 S.H. De Bruin, L.H.M. Janssen and G.A.J. van Os, Interaction of 2,3-diphosphoglycerate with human deoxy and oxyhemoglobin. Biochem. Biophys. Res. Com., 1973, 55, 193-199.

12 H.M. Dintzis, 1952, Studies of dielectric properties of human serum mercaptalbumin solutions, Ph.D. thesis, Harvard University, USA

13 P.D. Boyer, Spectroscopic study of the reaction of protein sulfhydryl groups with organic mercurial. J. Am. Chem. Soc., 1954, 76, 4331-4336

14 K.O. Okonjo and T.O. Okia, Haemoglobins with multiple reactive sulphydryl groups: the reaction of pigeon haemoglobin with 5, 5'-dithiobis (2-nitrobenzoic acid). J. Prot. Chem., 1993, 12, 1-8.
15 B.E. Hallaway, B.E. Hedlund and E.S. Benson, Studies on the effect of reagent and protein charges on reactivity of the $\beta 93$ sulfhydryl group of human hemoglobin using selected mutations, Arch. Biochem. Biophys., 1980, 203, 332-342.

16 J.M. Wilson, R.J. Bayer, D.J. Hupe, Structure-reactivity correlations for the thiol-disulphide interchange reaction, J. Am. Chem. Soc., 1977, 99, 7922-7926.

17 K.O. Okonjo, A. Taiwo, M. Balogun and O.B. Ekisola, Reactivities of the sulphydryl groups of dog hemoglobin, Biochim. Biophys. Acta, 1979, 576, 30-38.

18 R.L. Thurlkill, G.R. Grimsle, J.M. Scholtz and C.N. Pace, pK values of the ionizable groups of proteins, Prot. Sc., 2006, 15, 1214-1218.

19 M. Eigen and E.M. Eyring, Fast reactions in aqueous solutions of aminobenzoic acids. Am. Chem. Soc., 1962, 84, 3254-3256.

20 M. Eigen, G.G. Hammes and K. Kustin, Fast reactions of imidazole studied with relaxation spectrometry. J. Am. Chem. Soc., 1960, 82, 3482-3483.

21 B. Shaanan, Structure of human oxyhaemoglobin at $2.1 \AA$ A resolution. J. Mol. Biol., 1983, 171, 31-59.

22 K.O. Okonjo, FJ. Vega-Catalan and C.O. Ubochi, Temperature-jump studies on hemoglobin: kinetic evidence for a non-quaternary isomerization process in deoxy- and carbonmonoxyhemoglobin. J. Mol. Biol. 1989, 208, 347-354.

23 J.S. Olson and Q.H. Gibson, The functional properties of hemoglobin Bethesda $\left(\alpha_{2} \beta_{2}{ }^{145 H i s}\right)^{*}$. J. Bio. Chem., 1972, 247, 3662-3670.

24 M.F. Perutz, J.E. Ladner, S.R. Simon and C. Ho, Influence of globin structure on the state of heme. I Human deoxyhemoglobin. Biochemistry, 1974, 13, 2163-2173.

25 G.L. Ellman, A colorimetric method for determining low concentrations of mercaptans, Arch. Biochem. Biophy.1958, 74, 443-450.

26 K.O. Okonjo, O.S. Bello and J.O. Babalola, Transition of hemoglobin between two tertiary conformations: the transition constant differs significantly for the major and minor hemoglobin of the Japanese quail (Cortunix cortunix japonica), Biochim. Biophys. Acta., 2008, 1784, $464-471$

27 K.O. Okonjo, I. Adeogun and J.O. Babalola, Transition of hemoglobin between two tertiary conformations: inositol hexakisphosphate increases the transition constant and the affinity of sheep hemoglobin for 5, 5'-dithiobis (2-nitrobenzoate). Biochim. Biophys. Acta, 2009, 1794, 398-409.

28 P. Eyer, F. Worek, D. Kiderlen, G. Sinko, A. Stuglin, V. Simeon-Rudolf and E. Reiner, Molar absorption coefficients for the reduced Ellman reagent: a reassessment. Anal. Biochem., 2003, 312, 224-227.

29 T. Kleinschmidt and G. Braunitzer, Primary structure of the hemoglobin from the Egyptian fruit bat (Rousettus aegyptiacus, Chiroptera), Hoppe Seyler's Z. Physiol. Chem., 1982, 363,1209-1215

30 T. Kleinschmidt, B. Koop and G. Braunitzer, The primary structure of a mouse-eared bat (Myotis velifer, Chiroptera) hemoglobin. Biol. Chem. Hoppe-Seyler, 1986, 367, 1243-1249

31 T. Kleinschmidt, B.F. Koop and G. Braunitzer, The primary structure of the pallid bat (Antrozous pallidus, Chiroptera) hemoglobin, Biol. Chem. Hoppe-Seyler, 1987, 368, 1197-1202

32 G.A.L. Singer, T. Kleinschmidt, J.D. Pettigrew and G. Braunitzer, The primary structure of the hemoglobin from the tomb bat (Taphozous georgianus, Microchiroptera) Biol. Chem. Hoppe-Seyler, 1992, 373, 937-942

33 A.A. Fodeke, K.O. Oyedare and J.O. Babalola, Tertiary level $\mathrm{r} \leftrightarrow \mathrm{t}$ isomerization significantly raises the $\mathrm{pK}_{\mathrm{a}}$ of $\mathrm{CysF9}[93] \beta$ linked ionizable groups of straw-coloured fruit bat $\mathrm{Hb}$ : variation of apparent forward second-order rate constant with $\mathrm{pH}$, Int. J. Life Sci. 2016, 3, 171-179.

34 T.-Y. Fang, M. Zou, V. Simplaceanu, N.T. Ho and C. Ho, Assessment of roles of surface histidyl residues in the molecular basis of the Bohr effect and of $\beta 143$ histidine in the binding of 2,3-bisphosphoglycerate in human normal adult hemoglobin, Biochemistry, 1999, 38, 1342313432.

35 J.F. Taylor, E. Antonini, M. Brunori and J. Wyman, Studies on human hemoglobin treated with various sulfhydryl reagents, J. Biol. Chem. 1966, 241, 241-248.

36 K.O. Okonjo, Bohr effect of hemoglobins: accounting for the difference in magnitude. J. Theo. Bio. 2015, 380, 436-443. 